05,13

\title{
Структурные особенности и магнитные свойства пленок Со-W
}

\author{
(C) В.О. Васьковский ${ }^{1,2}$, М.Н. Волочаев ${ }^{3}$, А.Н. Горьковенко ${ }^{1}$, Е.А. Кравцов ${ }^{1,2}$, \\ В.Н. Лепаловский ${ }^{1}$, А.А. Фещенко ${ }^{1, \uparrow}$ \\ ${ }^{1}$ Уральский фредеральный университет, \\ Екатеринбург, Россия \\ ${ }^{2}$ Институт ффизики металлов УрО РАН, \\ Екатеринбург, Россия \\ ${ }^{3}$ Институт физики СО РАН, \\ Красноярск, Россия \\ ฯ E-mail: asynikname@mail.ru
}

Поступила в Редакцию 5 марта 2021 г.

В окончательной редакции 5 марта 2021 г.

Принята к публикации 8 марта 2021 г.

Исследованы структура и магнитные свойства тонких поликристаллических пленок $\mathrm{Co}_{100-x} \mathrm{~W}_{x}$ $(0 \leq x \leq 30)$, осажденных методом магнетронного распыления на стеклянные подложки, в том числе содержащие буферные слои Ta, W, Ru. Установлено что пленки чистого Со неоднофазны и содержат ГПУ- и ГЦК-кристаллические модификации. Легирование ведет к повышению концентрации ГЦК-фазы и усилению текстуры типа (111), а в последующем к аморфизации пленок. На глубину и концентрационную локализацию указанных преобразований определенное влияние оказывают буферные слои. Характерной особенностью магнетизма пленок $\mathrm{Co}-\mathrm{W}$ является значительная перпендикулярная составляющая в макроскопической магнитной анизотропии, приводящая к „закритическому“ магнитному состоянию. Показано, что ее источником выступает текстурированная ГЦК-фаза, кристаллическая анизотропия которой усиливается в результате легирования кобальта вольфрамом.

Ключевые слова: пленка, легирование, подложка, структура, магнитные свойства.

DOI: 10.21883/FTT.2021.07.51042.046

\section{1. Введение}

Проблема высокоплотной магнитной записи информации [1-3] стимулирует поиск пленочных сред с сильной магнитной анизотропией, в том числе имеющей одноосный характер и нормальную по отношению к поверхности ориентацию оси легкого намагничивания (перпендикулярную анизотропию). Среди материалов, потенциально пригодных в пленочном состоянии на эту роль, рассматриваются аморфные сплавы $3 d$-металлов с редкоземельными элементами, например, Tb-Co [4], a также поликристаллические сплавы Co с $4 d$ - или $5 d$-переходными металлами, в том числе системы с Mo, W, Pt [5-8]. В первом случае перпендикулярная макроскопическая анизотропия связывается со специфической (столбчатой) неоднородностью микроструктуры и становится определяющей только вблизи состояния магнитной компенсации, свойственного ферримагнитным системам с тяжелыми редкоземельными элементами [9]. Околокомпенсационная область характеризуется низкой спонтанной намагниченностью, и в этом компоненте вышеуказанные пленки уступают второму типу пленочных сред, в формировании магнитной анизотропии которых важная роль отводится кристаллической анизотропии [10]. Считается, что кристаллическая анизотропия, присутствующая в Со за счет спин-орбитальной связи, усиливается при легировании из-за гибридизации энергетических $d$-зон различных переходных элементов. Однако фазовое разделение также имеет место в подобных сплавах, и в некоторых случаях оно может оказаться доминирующим мотивом в механизме магнитной анизотропии [11].

Неотъемлемым атрибутом тонкопленочного состояния материалов является подложка. Среди прочего она оказывает значительное, а порой определяющее влияние на структурно-фазовое состояние металлических осадков. При использовании стеклянных подложек их структурообразующая роль может регулироваться за счет дополнительных, так называемых буферных покрытий $[12,13]$. Настоящая работа посвящена экспериментальному исследованию особенностей структурных и магнитных свойств пленок системы $\mathrm{Co}-\mathrm{W}$ на стеклянных подложках, в том числе с различными буферными покрытиями.

\section{2. Методические аспекты}

Пленки сплавов $\mathrm{Co}-\mathrm{W}$ были получены методом магнетронного распыления на установке Orion-8 в режиме сораспыления мишеней Со и $\mathrm{W}$ при давлении остаточных газов $5 \cdot 10^{-5} \mathrm{~Pa}$ и давлении рабочего газа аргона $3 \cdot 10^{-3}$ Ра. Подложками служили покровные стекла Corning в исходном виде или покрытые буферными слоями Ta, W, Ru. Осаждение материалов проходило 
в условиях высокочастотного электрического смещения подложек и наличия в их плоскости однородного магнитного поля (технологическое поле) напряженностью 250 Ое. Содержание W в образцах варьировалось в пределах $0 \div 30$ at.\% за счет изменения соотношения скоростей распыления соответствующих мишеней. Контроль состава осуществлялся на рентгенофлуоресцентном спектрометре Nanohunter с погрешностью \pm 0.1 at.\%. Номинальная толщина буферных и магнитных слоев составляли 5 и $50 \mathrm{~nm}$ соответственно. Структурные исследования осуществлялись на дифрактометре Empyrean в излучении СоК $\alpha$ и просвечивающем электронном микроскопе Hitachi HT7700 TEM. Для изучения магнитных свойств и наблюдения доменной структуры привлекались Керр-магнитометр EvicoMagnetics, сканирующий силовой микроскоп NT-MDT NTEGRA-Prima, вибромагнитометр LakeShore.

\section{3. Представление и анализ полученных результатов}

Основной задачей настоящей работы являлось выяснение закономерностей структурных преобразований и формирования магнитных свойств в тонких пленках $\mathrm{Co}-\mathrm{W}$ в связи с модификацией поверхности подложек, на которые они осаждались, толщиной, а также при термических воздействиях. Указанная модификация осуществлялась путем нанесения на поверхность покровных стекол тонких слоев различных металлов. Для этой цели использовались Тa, W или Ru. Bсе эти металлы тугоплавки, не склонны к диффузии при контакте с другими металлами, а в качестве буферных слоев, так или иначе, опробованы как фактор влияния на свойства магнитных пленок. В частности, Та широко применяется при получении многослойных магнитных структур с эффектом гигантского магнитосопротивления [14-16]. Несмотря на собственное ОЦК-строение, он в форме тонких практически аморфных слоев способствует формированию ГЦК-структуры и текстуры типа (111) в прилегающих поликристаллических слоях ряда магнитных металлов и сплавов. Имеются сведения и об использовании $\mathrm{W}$ в качестве материала структурообразующего буферного слоя. Он, как и Та, обладает ОЦК-кристаллической решеткой, но применялся для выращивания псевдомонокристаллических пленок Gd c ГПУ-структурой [17]. Для Ru, в отличие от двух других металлов, свойственна ГПУ-структура, и $\mathrm{Ru}$-содержащие буферные слои не причисляются к эффективным факторам влияния на смежные слои, по крайней мере, с ГЦК-структурой [17]. Таким образом, представленный набор металлов для буферных слоев отвечал задаче широкого варьирования структурообразующих свойств подложек.

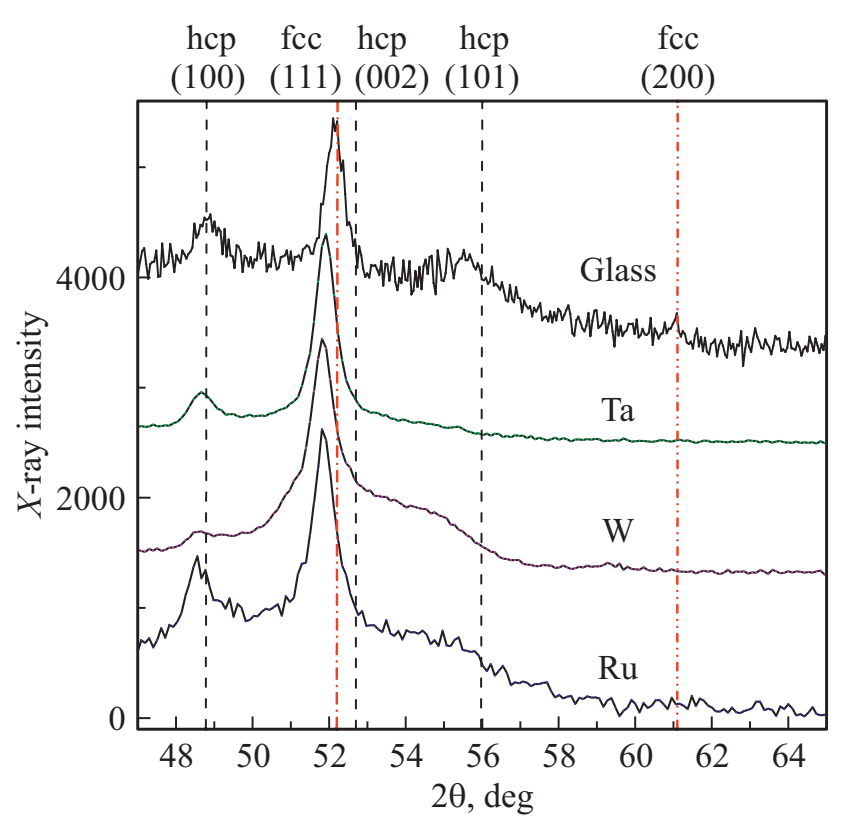

Рис. 1. Дифрактограммы пленок Со на разных подложках. Пунктиром показано положение дифракционных линий массивных $\alpha$-Co (hcp) и $\beta$-Co (fcc).

\section{1. Кристаллическая структура и магнитные свойства пленок Со на различных подложках}

Естественному состоянию Со при комнатной температуре соответствует гексагональная плотноупакованная (ГПУ) кристаллическая решетка - так называемый $\alpha$-Сo, а при температуре выше $700 \mathrm{~K}$ - кубическая гранецентрированная (ГЦК) кристаллическая решетка или $\beta$-Со. Однако в пленочном состоянии в силу специфики образования металлических осадков в конкретных технологических условиях, в том числе за счет влияния подложки, структура Со может отличаться от равновесной. В этой связи для разделения влияния факторов буферного слоя и легирования целесообразно сопоставить свойства пленок чистого Со на разных подложках. Соответствующие дифрактограммы в области углов, содержащих определенно фиксируемые рефлексы, показаны на рис. 1. На нем же отмечены положения линий массивного Со в двух модификациях. Представленная дифракционная картина говорит о качественном подобии пленок на разных подложках, но оставляет место для дискуссии о структурном состоянии самого Со.

С одной стороны, линия около угла $2 \theta=49^{\circ}$, скорее всего, принадлежат $\alpha$-Со и формируется кристаллографическими плоскостями (100). К этой же модификации можно отнести слабовыраженное возмущение, наблюдаемое на дифрактограммах вблизи $2 \theta=56^{\circ}$, и приписать его отражениям от плоскостей (101). С другой стороны, линия около $2 \theta=52^{\circ}$ тяготеет как к плоскостям (002) $\alpha$-Со, так и к плоскостям (111) $\beta$-Со, хотя и с несколько увеличенными параметрами решеток. Последнее может 

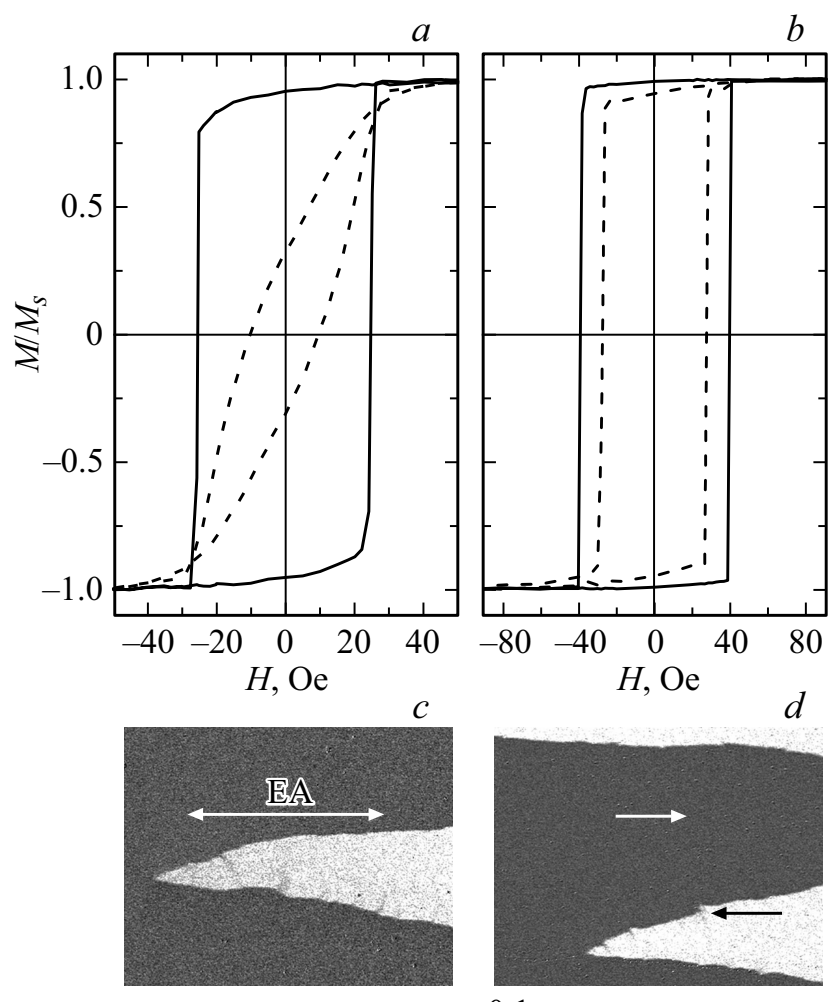

$0.1 \mathrm{~mm}$

Рис. 2. Магнитооптические петли гистерезиса, измеренные вдоль (сплошные кривые) и перпендикулярно (пунктирные кривые) оси технологического поля, и изображения доменов для пленок Со на стекле $(a, c)$ и на буферном слое $\mathrm{Ru}(b, d)$. Двойная стрелка указывает ориентацию оси легкого намагничивания (EA), одинарные - ориентацию намагниченности в доменах.

быть следствием остаточных напряжений, возникших в металлических пленках при их формировании на диэлектрических подложках. Заметим, что сдвиг реальной линии по отношению к ее соответствующим базовым положениям в разных модификациях будет заметно меньше, если приписать ее кубическому Со. Кроме того, линия (111) в дифрактограмме изотропного поликристаллического $\beta$-Со должна иметь наибольшую относительную интенсивность. В то же время для $\alpha$-Со наибольшая относительная интенсивность присуща линии (101), а линия (002) должна быть многократно слабее. Правда, в случае тонких пленок соотношение интенсивностей дифракционных линий нельзя считать однозначным структурным критерием, так как оно искажается при возникновении кристаллической текстуры, часто наблюдающейся в пленках. В целом полученная информация приводит к заключению, что исследованные пленки, скорее всего, неоднофазны и содержат Со двух модификаций. При этом наличие буферных покрытий играет второстепенную роль в формировании собственно кристаллической структуры, но, по-видимому, оказывает определенное влияние на соотношение объемов разных фаз и их текстуру.

Последнее косвенным образом подтверждается существенным различием в гистерезисных свойствах пленок на разных подложках. Это, в частности, видно из сравнения магниоооптических петель гистерезиса образцов на стекле и $\mathrm{Ru}$, показанных на рис. $2, a, b$. Первые демонстрируют наличие выраженной магнитной анизотропии в плоскости. Это так называемая М-наведенная анизотропия - типичное свойство поликристаллических пленок $3 d$-металлов и их сплавов [18]. Она относительно невелика, носит одноосный характер и формируется в состоянии магнитного насыщения, которое обеспечивается технологическим магнитным полем при получении пленочных образцов. Вторые показывают значительно меньшую анизотропию. Фактически наведенная анизотропия нивелируется на фоне большой коэрцитивной силы, свойственной этим пленкам. Однако, не смотря на почти двукратное различие в коэрцитивной силе, характер перемагничивания образцов обоих типов вдоль оси легкого намагничивания (ЕA), которая совпадает с осью приложения технологического поля, практически одинаков. Оно осуществляется путем скачкообразно смещения зигзагообразного магнитного фронта (рис. 2, $c, d$ ). Пленки Со на Та и W демонстрируют гистерезисные свойства близкие к свойствам образцов на стекле и $\mathrm{Ru}$ соответственно.

\section{2. Магнитные свойства пленок Co-W на различных подложках}

Наиболее яркими закономерностями в изменении магнитных свойств пленок бинарной системы $\mathrm{Co}_{100-x} \mathrm{~W}_{x}$ являются быстрое, близкое к линейному уменьшение спонтанной намагниченности при увеличении концентрации $\mathrm{W}$ и многократный рост коэрцитивной силы, но в ограниченной области составов вблизи $x \sim 10$. На рис. 3 на примере пленок, осажденных на стекло и на $\mathrm{Ru}$, показаны концентрационные зависимости намагниченности насыщения $M_{s}(x)$. Как видно, для образцов двух характерных типов они практически совпадают и иллюстрируют тенденцию к переходу в немагнитоупорядоченное состояние при $x \geq 30$. Столь резкое падение намагниченности свидетельствует об уменьшении среднего магнитного момента, приходящегося на атом Со. Это, в свою очередь, подтверждает представление о существенной модификации $3 d$-зоны ферромагнетика, происходящей за счет $5 d$-электронов $\mathrm{W}$, и подчеркивает ее независимость от вероятных особенностей микроструктуры пленок на разных подложках.

В отличие от спонтанной намагниченности магнитный гистерезис относится к числу структурно-чувствительных явлений и требует более детального рассмотрения. На рис. 4 показаны зависимости коэрцитивной силы пленок $\mathrm{Co}_{100-x} \mathrm{~W}_{x}$ для тех же образцов, значения $M_{s}$ которых показаны на рис. 3. По виду обе кривые $H_{c}(x)$ подобны и характеризуются наличием выраженных макси- 


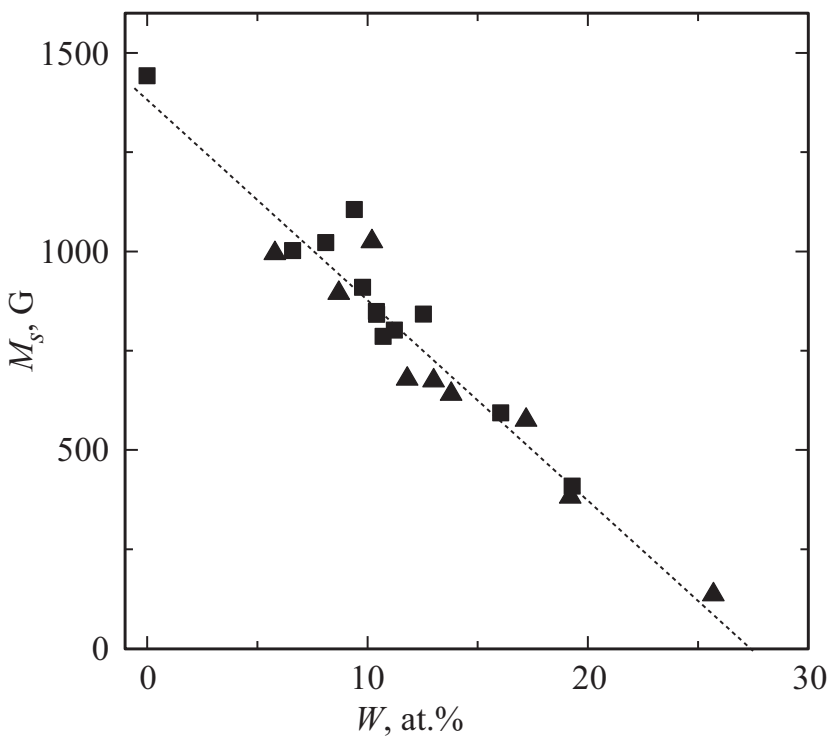

Pис. 3. Зависимости спонтанной намагниченности от содержания вольфрама в пленках бинарной системы $\mathrm{Co}-\mathrm{W}$, осажденных на стекло (квадратики) и $\mathrm{Ru}$ (треугольники).

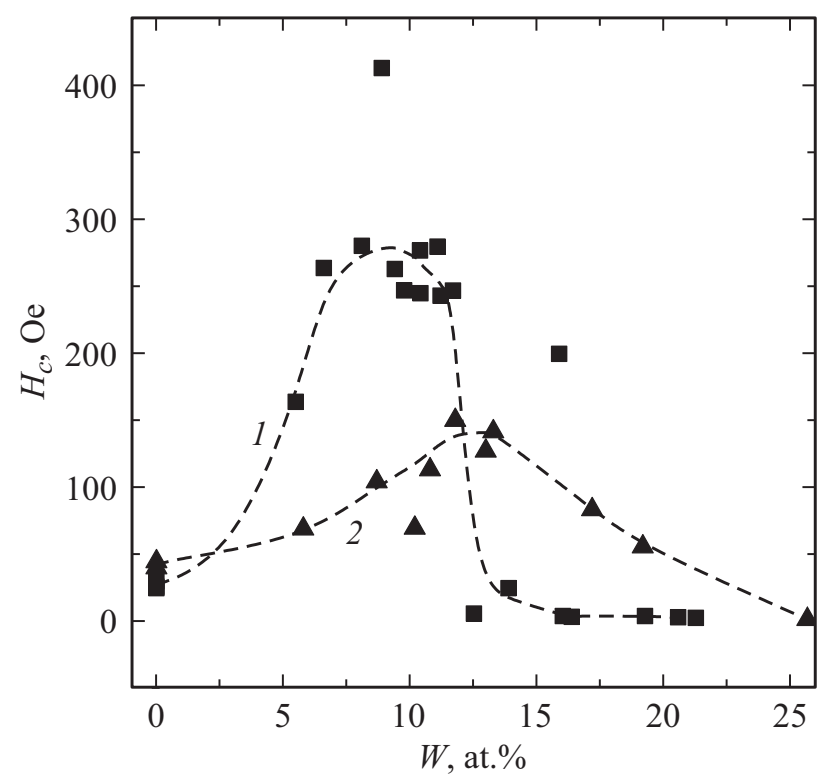

Рис. 4. Концентрационные зависимости коэрцитивной силы образцов $\mathrm{Co}_{100-x} \mathrm{~W}_{x}$ на стекле (кривая 1) и на $\mathrm{Ru}$ (кривая 2).

мумов. Однако в количественном отношении, не смотря на наличие выбросов экспериментальных точек, можно говорить об их существенном различии. Для пленок на стекле максимальные значения коэрцитивной силы $H_{c}$ в среднем в два раза больше, а концентрационный интервал высоких $H_{c}$ заметно уже и сдвинут в область меньших концентраций W. Очевидно, что обсуждение причин таких различий целесообразно предварить более подробным анализом влияния легирования на гистерезисные свойства пленок Со в рамках образцов одного типа.
На рис. 5, a представлена магнитооптическая петля пленки $\mathrm{Co}-\mathrm{W}$ на стекле, содержащей около 10 ат.\% легирующего элемента, измеренная вдоль оси приложения технологического поля. Сравнение с соответствующей петлей для пленки чистого Со (рис. 2,a) показывает, что введение $\mathrm{W}$ не только на порядок увеличивает коэрцитивную силу, но и изменяет форму самой петли. На ней появляются протяженные наклонные участки, которые оканчиваются переходом в состояние магнитного насыщения в поле, превышающем $2 \mathrm{kOe}$, то есть на два порядка большем поля насыщения типичного для однокомпонентной пленки. При этом магнитная анизотропия в плоскости не наблюдается. Данные особенности перемагничивания характерны для так называемого „закритического“ магнитного состояния [19]. В отсутствие внешнего поля оно соответствует неоднородной магнитной структуре типа „страйп-домены“. Намагниченность в „страйпах“ ориентирована подуглом к плоскости пленки так, что ее планарная компонента в соседних доменах одинакова, а нормальная имеет разный знак.
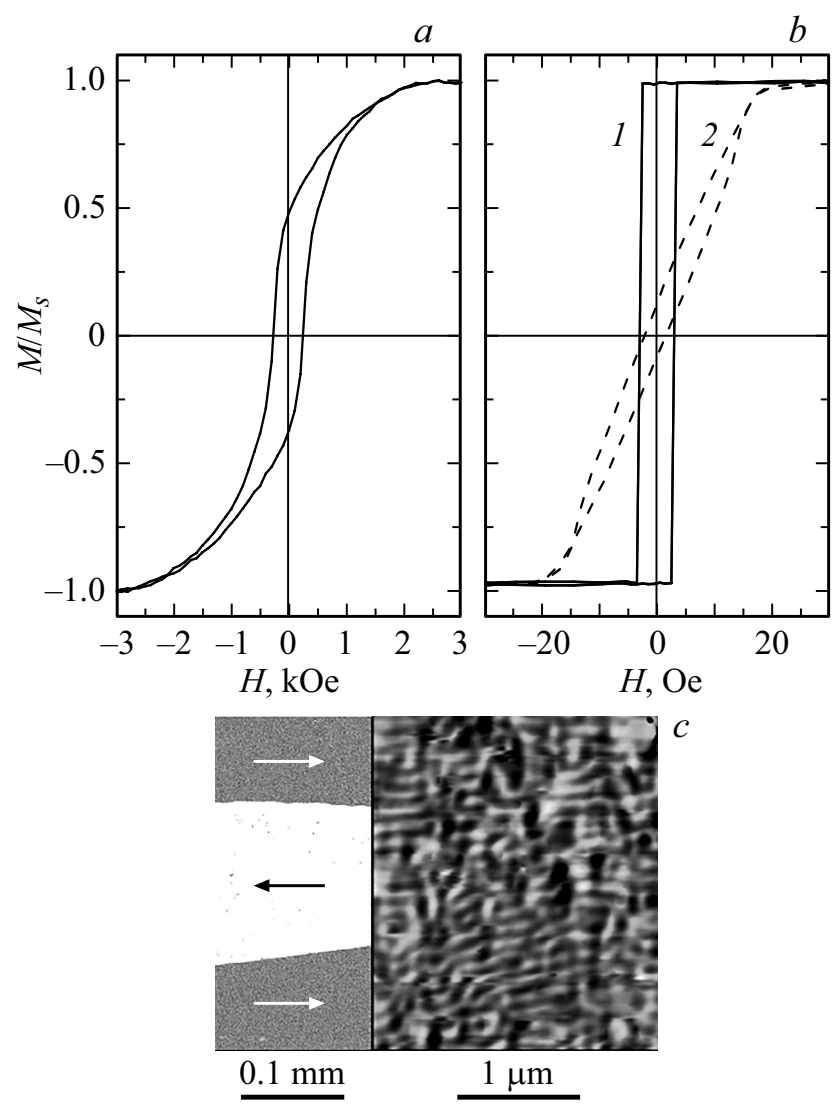

Рис. 5. Магнитооптические петли гистерезиса пленок $\mathrm{Co}-\mathrm{W}$ на стекле, содержащих $9.8(a)$ и $16(b)$ at.\% W, измеренные вдоль (кривые 1) и перпендикулярно (кривая 2) оси технологического поля. Доменная структура $(c)$ выявленная магнитооптическим (слева) и магнитосиловым (справа) методами в образце с $x=9.8$. Стрелками показана ориентация результирующей намагниченности в макродоменах. 
Типичные значения коэрцитивной силы пленок $\mathrm{Co}_{100-x} \mathrm{~W}_{x}$ на различных подложках

\begin{tabular}{c|c|c|c|l}
\hline Подложка & $\begin{array}{c}\left(H_{c}\right)_{\max }, \\
\text { Oe }\end{array}$ & $x$ & $\begin{array}{c}\left(H_{c}\right)_{\min }, \\
\text { Oe }\end{array}$ & $x$ \\
\hline Glass & 412 & 8.9 & 2.5 & 16.4 \\
$\mathrm{Ta}$ & 451 & 8.0 & 2.2 & 18.5 \\
$\mathrm{~W}$ & 474 & 13.5 & 3 & 24 \\
$\mathrm{Ru}$ & 149 & 11.8 & 0.5 & 25.7
\end{tabular}

Магнитооптическое изображение доменной структуры данного образца в размагниченном состоянии показано на левой части рис. 5, $c$.Как видно, это широкие полосовые домены. Однако методика магнитосиловой микроскопии показывает, что эти домены обладают субструктурой (рис. 5, $c$, правая часть), которая не выявляется с помощью эффекта Керра из-за высокой дисперсности. Таким образом, можно заключить, что магнитооптический контраст отображает структуру макродоменов с разной ориентацией планарной компоненты намагниченности, а магнитосиловой - структуру микродоменов типа „страйпов“. Правда в данном случае „страйп-структура“" не отличается высокой регулярностью, характерной для магнитомягких пленок типа пермаллоя [20]. Это может быть связано с поликристалличностью и относительно высокой кристаллической анизотропией исследуемых объектов, а также с их неоднофазностью.

Как следует из рис. 4, для образцов на стекле концентрационная область с высоким гистерезисом невелика. При достижении $x \sim 13 \div 15$ коэрцитивная сила резко снижается до уровня в несколько эрстед, то есть становится много меньше даже тех значений $H_{c}$, которые свойственны пленкам чистого Со. На рис. $5, b$ показаны магнитооптические петли одного из таких образцов. Они свидетельствуют о восстановлении одноосной магнитной анизотропии в плоскости пленки и в целом о характере перемагничивания, свойственного магнитомягким пленочным средам. Интересно, что при сопоставимых значениях коэрцитивной силы величина поля анизотропии пленок $\mathrm{Co}-\mathrm{W}$ значительно выше, чем в пленках пермаллоя или метглассов [21].

Возвращаясь к обсуждению роли подложки в формировании гистерезисных свойств пленок $\mathrm{Co}-\mathrm{W}$, нужно констатировать, что буферные слои Та и $\mathrm{W}$ приводят к зависимостям $H_{c}(x)$ по характеру подобным тем, что показаны на рис. 4. В количественном же отношении они занимают некую промежуточную позицию. Для иллюстрации в таблице приведены экстремальные значения коэрцитивной силы и составы, при которых они реализовывались. Из ее анализа, в частности, следует, что пленки на Та по своим свойствам тяготеют к пленкам на стекле, а на $\mathrm{W}$ - к пленкам на Ru. Таким образом, при определенной схожести концентрационного изменения гистерезисных свойств пленок $\mathrm{Co}-\mathrm{W}$ разного типа налицо и их значительная специфика, которую целесообразно связать с особенностями структурного состояния пленок на разных подложках.

\section{4. Кристаллическая структура пленок Co-W на различных подложках}

На рис. 6 приведены дифрактограммы образцов, содержащих металлические буферные слои, состав которых соответствует областям наибольшего магнитного гистерезиса. Сравнивая их с аналогичными данными для пленок чистого Со (рис. 1), можно констатировать следующее. Общая дифракционная картина осталась неизменной. В ней по-прежнему присутствуют линии, которые можно трактовать как следствие структурной двуфазности (ГЦК- и ГПУ-фазы) пленок. Вместе с тем можно отметить тенденцию к сдвигу линий в область меньших углов дифракции, что свидетельствует об ожидаемом увеличении межплоскостных расстояний при внедрении в решетку Со атомов W большего размера. Кроме того, наблюдается некоторое изменение в соотношении интенсивностей линий в пользу наиболее яркой из них, которое может говорить о перераспределении в объемах фаз и усилении кристаллической текстуры. Причем эта особенность в большей мере выражена для пленок на буферном слое $\mathrm{W}$ и в наименьшей - на $\mathrm{Ru}$.

Пленки на стекле при легировании показали несколько иное изменение структуры. Как следует из дифрактограммы, представленной на рис. 7, $a$ (кривая 1 ), в области малых углов дифракции присутствует только одна относительно узкая и высокоинтенсивная линия. Зато четко обозначилась линия в области больших углов

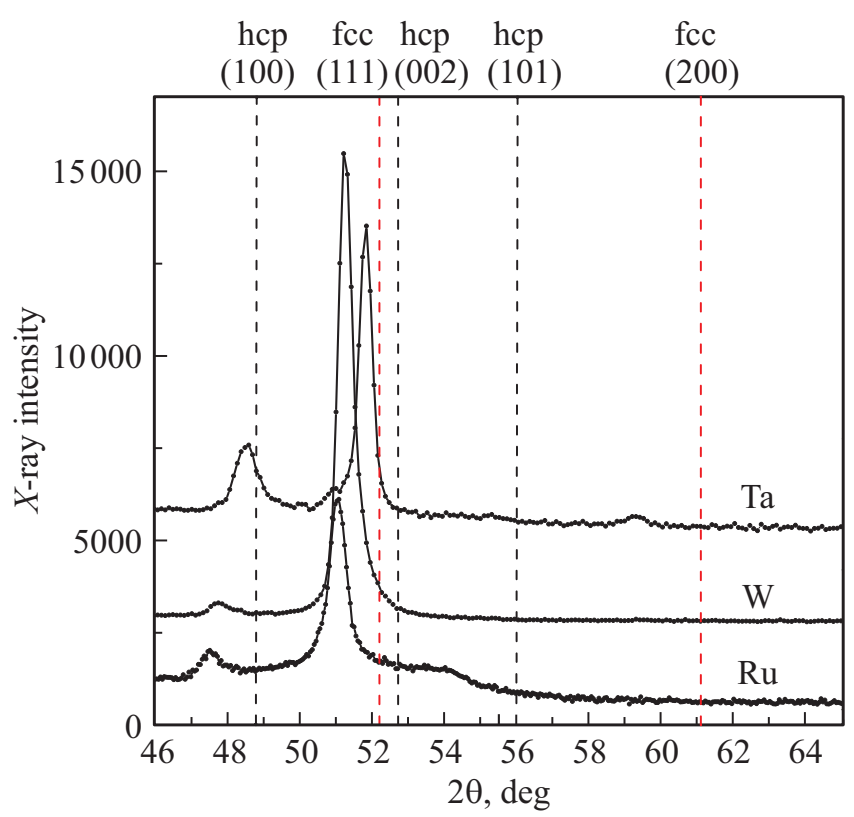

Рис. 6. Дифрактограммы пленок $\mathrm{Co}-\mathrm{W}$ на подложках с буферными слоями Тa, W, Ru и концентрацией вольфрама 8; $13.5 ; 13.3$ at.\% соответственно. Пунктиром показано положение дифракционных линий массивных $\alpha$-Co (hcp) и $\beta$-Co (fcc). 

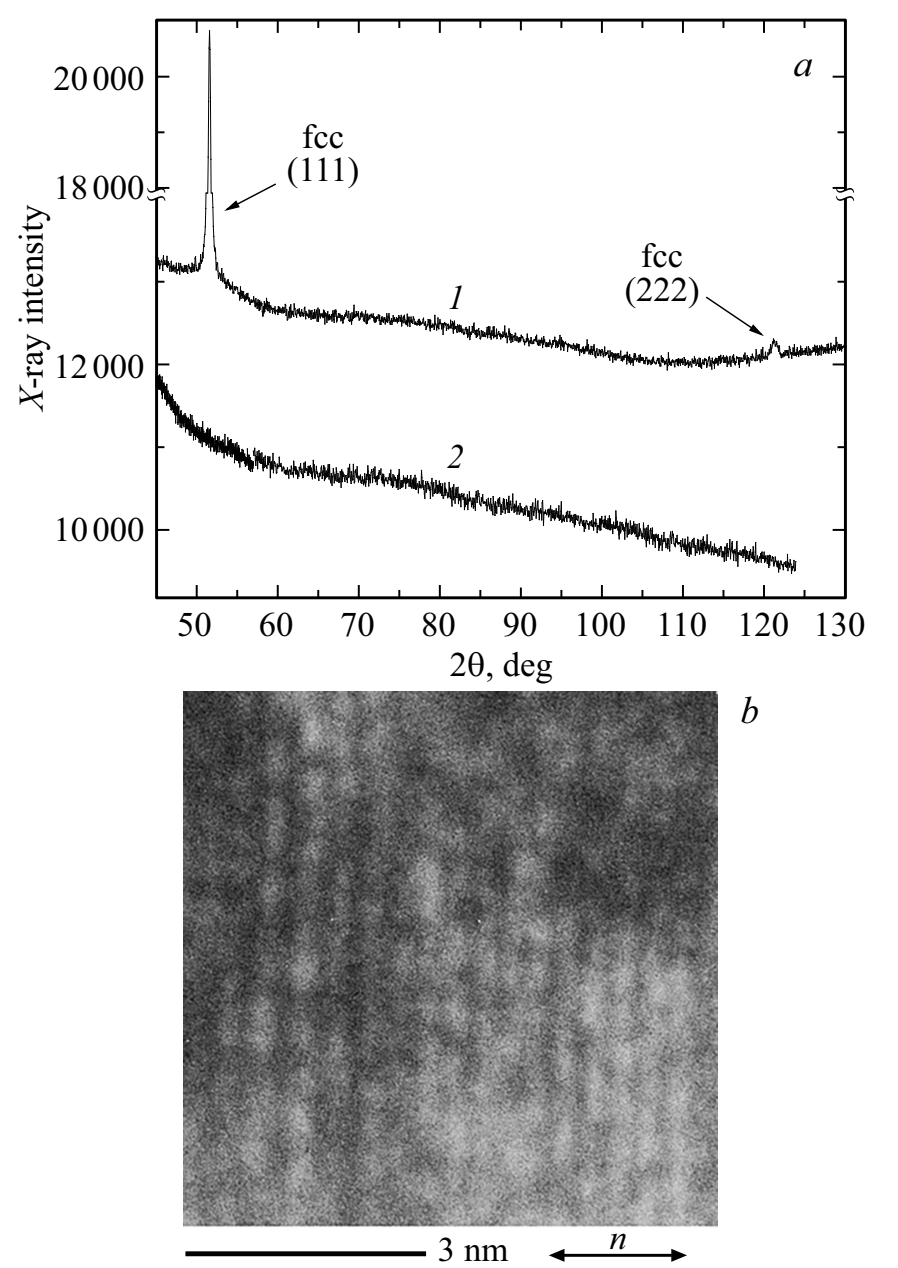

Рис. 7. Дифрактограммы (a) и ПЭМ-изображение $(b)$ пленок $\mathrm{Co}-\mathrm{W}$ на подложках без буферных покрытий с концентрацией $\mathrm{W}: a 1-10.4 ; a 2-16 ; b-11.1$ at.\%. Стрелкой с обозначением $n$ показана ориентация нормали к плоскости пленки.

дифракции. В совокупности эти линии можно идентифицировать как 1-ый и 2-ой порядки отражений от плоскостей (111) ГЦК кристаллической решетки в условиях высокой кристаллической текстуры. Оценка параметра решетки дает величину $0.3558 \mathrm{~nm}$, что сопоставимо с характеристикой решетки кубического Со $(0.3521 \mathrm{~nm})$. Заключение о высокой степени кристаллической текстуры нашло свое подтверждение и по данным, полученными с помощью просвечивающей электронной микроскопии (ПЭМ) высокого разрешения. На рис. 7, $b$ приведен фрагмент ПЭМ-изображения поперечного среза пленки. На нем на фоне пятен разной яркости достаточно хорошо видны закономерно расположенные темные вертикальные полосы. Области нерегулярного контраста можно рассматривать как отображение кристаллитов, а полосы - атомных плоскостей. Близость атомных плоскостей в кристаллитах указывает на достаточно совершенную кристаллическую текстуру.
Следует также отметить, что слабовыраженные дифракционные линии в области $2 \theta \sim 120^{\circ}$ зафиксированы и на пленках других типов. Это дает дополнительные аргументы в пользу того, чтобы связывать наиболее яркую линию на всех представленных выше дифрактограммах с ГЦК-кристаллической решеткой. На рис. 7, $a$ также представлен пример дифрактограммы образца с относительно большим содержанием W. Как видно, на ней вообще нет локализованных дифракционных рефлексов, что говорит о реализации аморфоподобного состояния. Эта дифрактограмма относится к пленк $\mathrm{Co}_{84} \mathrm{~W}_{16}$ на стекле. Для образцов других типов наблюдается аналогичная структурная трансформация, но критическая концентрация $\mathrm{W}$, при которой это происходит, в некоторой степени зависит от наличия и состава

бу0ферного слоя. В частности, пленки на стекле и Та аморфизуются при $x \geq 12 \div 13$, на W и $\mathrm{Ru}$ при $x \geq 15 \div 20$.

\section{5. Заключение}

Вся совокупность представленных результатов позволяет составить достаточно цельную картину структурных особенностей пленок системы $\mathrm{Co}-\mathrm{W}$, полученных магнетронным распылением, и оценить их влияние на макроскопические магнитные свойства. Главными факторами такого влияния являются неоднофазность и кристаллическая текстура. В пленках чистого Со независимо от типа подложки присутствуют кристаллиты ГПУи ГЦК-модификаций. Причем, как минимум, последняя имеет выраженную кристаллическую текстуру типа (111). Однако относительная концентрация этих фаз может варьироваться за счет введения буферных покрытий. В ряду опробованных вариантов ГПУ-фаза, которая характеризуется одноосной и достаточно сильной анизотропией (константа анизотропии $K=4 \cdot 10^{6} \mathrm{erg} / \mathrm{cm}^{3}$ ), большую концентрацию, по-видимому, имеет в пленках на $\mathrm{W}$ и $\mathrm{Ru}$, задавая повышенный уровень магнитного гистерезиса. В пленках на стекле и на Та гистерезис существенно меньше, что может свидетельствовать о преобладании ГЦК-фазы, имеющей более слабую четырехосную магнитную анизотропию.

Добавка W в некотором интервале концентраций приводит к постепенному перераспределению объемов фаз в пользу ГЦК-составляющей. Наиболее глубоко эта структурная модификация проходит в образцах на стекле, которые при содержании $\mathrm{W} \sim 10$ at.\% становятся практически однофазными и высокотекстурованными. Интересно, что вслед за этим в узком концентрационном интервале (2-3 at.\%) следует полное разрушение кристалличности. В легированных пленках на Та и W неоднофазность в небольшой мере сохраняется вплоть до перехода в аморфное состояние, который к тому же растягивается на более широкий интервал составов. Наибольшую устойчивость к концентрационным структурным преобразованиям демонстрируют пленки на Ru. 
Для них значительная неоднофазность сохраняется во всей области кристаллического состояния, а аморфизация происходит при концентрации $W>20$ ат.\%.

Концентрационные изменения магнитных свойств пленок $\mathrm{Co}-\mathrm{W}$ достаточно хорошо коррелируют с описанными структурными преобразованиями. Наиболее характерной чертой магнетизма легированных пленок всех типов является „закритическое“ состояние. Как известно [19], оно трактуется как результат компромисса между анизотропией формы пленок и перпендикулярной магнитной анизотропией структурного происхождения. Применительно к исследуемой системе $\mathrm{Co}-\mathrm{W}$ его образование можно рассматривать как свидетельство возникновения или усиления перпендикулярной составляющей магнитной анизотропии на фоне уменьшения вклада от эффекта саморазмагничивания из-за снижения спонтанной намагниченности. Часто встречающейся структурной неоднородностью, ответственной за перпендикулярную магнитную анизотропию в поликристаллических металлических пленках, является так называемая столбчатая микроструктура [22]. Однако в исследуемых объектах она не выявлена. В этой связи акцент целесообразно сделать на кристаллическую магнитную анизотропию, причем не в рамках ГПУ структуры, как, например, указывается в [23], а применительно к реально наблюдающейся ГЦК структуре. При этом можно полагать, что усиление перпендикулярной анизотропии, связанной с осью легкого намагничивания типа [111], при легировании происходит как за счет повышения текстуры типа (111), так и за счет увеличения константы кристаллической анизотропии. Выполненные нами оценки показывают, что в пленках на стекле $K$ достигает значений $1.5 \cdot 10^{6} \mathrm{erg} / \mathrm{cm}^{3}$, что нетипично для ГЦК структуры и сопоставимо с характеристиками гексагонального Сo.

Таким образом, „закритическое“ магнитное состояние и свойственный ему высокий магнитный гистерезис, связываются нами с кристаллической магнитной анизотропией ГЦК-фазы. Она формируется на основе ГЦК-решетки Со и модифицируется за счет внедрения W. Образованию и текстурированию такой фазы способствует или препятствует структурообразующее действие подложки. Именно данный фактор обуславливает специфику магнитных свойств пленок, осажденных на разные буферные слои. Это, в частности, относится и к различиям в эффекте концентрационной аморфизации, который, по-видимому, отражает превышения предела растворимости $\mathrm{W}$ в ГЦК-структуре и является причиной реализации магнитомягкого состояния в пленках $\mathrm{Co}-\mathrm{W}$.

\section{Благодарности}

Авторы выражают благодарность А.С. Болячкину, М.Е. Москалеву и В.В. Попову за помощь в организации работы и участие в обсуждении результатов.

\section{Финансирование работы}

Работа выполнена при финансовой поддержке Министерства науки и высшего образования Российской Федерации, тема № FEUZ-2020-0051.

\section{Конфликт интересов}

Авторы заявляют, что у них нет конфликта интересов.

\section{Список литературы}

[1] S.N. Piramanayagam. J. Appl. Phys. 102, 1, 011301 (2007).

[2] Ultra-high-density magnetic recording: storage materials and media designs/ Eds G. Vavaro, F. Casoli. CRC Press. (2016). $51 \mathrm{c}$.

[3] L. Saharan, C. Morrison, Y. Ikeda, K. Takano, J.J. Miles, T. Thomson, T. Schref, G. Hrkac. Appl. Phys. Lett. 102, 14, 142402 (2013).

[4] R.H. Krider. Ann. Rev. Mater. Sci. 23, 1, 411 (1993).

[5] K. Oikawa, G. W. Qin, M. Sato, O. Kitakami, Y. Shimada. Appl. Phys. Lett. 83, 5, 966. (2003).

[6] D.Z. Grabco, I.A. Dikusa, V.I. Petrenko, E.E. Harea, O.A. Shikimaka. Surface Eng. Appl. Electrochem. 43, 1, 11 (2007).

[7] D.A. Dugato, J. Brandão, R.L. Seeger, F. Béron, J.C. Cezar, L.S. Dorneles, T.J.A. Mori. Appl. Phys. Lett. 115, 18, 182408 (2019).

[8] T.R. Gao, Y.Q. Wu, S. Fackler, I. Kierzewski, Y. Zhang, A. Mehta, M.J. Kramer, I. Takeuchi. Appl. Phys. Lett. 102, 2, 022419 (2013).

[9] В.О. Васьковский, А.Н. Горьковенко, О.А. Аданакова, А.В. Свалов, Н.А. Кулеш, Е.А. Степанова, Е.В. Кудюков, В.Н. Лепаловский. Физика металлов и металловедение 120, 11, 1151 (2019).

[10] A. Kashyap, P. Manchanda, P.K. Sahota, R. Skomski, J.E. Shield, D.J. Sellmyer. IEEE Transact. Magn. 47, 10, 3336 (2011).

[11] K. Oikawa, G.W. Qin, M. Sato, S. Okamoto, O. Kitakami, Y. Shimada. Appl. Phys. Lett. 85, 13, 2559 (2003).

[12] R. Jérome, T. Valet, P. Galtier. IEEE Transact. Magn. 30, 6, 4878 (1994).

[13] В.О. Васьковский, В.Н. Лепаловский, А.Н. Горьковенко, Н.А. Кулеш, П.А. Савин, А.В. Свалов, Е.А. Степанова, Н.Н. Щеголева, А.А. Ювченко. ЖТФ 85, 1, 118 (2015).

[14] S. Gangopadhyay, J.X. Shen, M.T. Kief, J.A. Barnard, M.R. Parker. IEEE Transact. Magn. 31, 6, 3933 (1995).

[15] R. Coehoorn . Giant magnetoresistance and magnetic interactions in exchange-biased spin-valves. Handbook of Magnetic Materials/ Ed. K.H.J. Buschow. North Holland, Amsterdam. (1999). 198 c.

[16] Н.С. Банникова, М.А. Миляев, Л.И. Наумова, Е.И. Патраков, В.В. Проглядо, И.Ю. Каменский, М.В. Рябухина, В.В. Устинов. Физика металлов и металловедение 119, 11, 1132 (2018).

[17] M. Farle. Rep. Prog. Phys. 61, 7, 755 (1998).

[18] А.Г. Лесник. Наведенная магнитная анизотропия в поликристаллических пленках. Наук. думка, Киев (1976). 163 с.

[19] Н.М. Саланский, М.Ш. Ерухимов. Физические свойства и применение тонких пленок. Наука, Новосибирск. (1975). $222 \mathrm{c}$. 
[20] В.О. Васьковский, П.А. Савин, С.О. Волчков, В.Н. Лепаловский, Д.А. Букреев, А.А. Бучкевич. ЖТФ 83, 1, 110 (2013).

[21] E.A. Mikhalitsyna, V.A. Kataev, A. Larrañaga, V.N. Lepalovskij, A.P. Turygin. J. Magn. Magn. Mater. 415, 61 (2016).

[22] S.R. Herd. J. Appl. Phys. 50, 3, 1645 (1979).

[23] S.Q. Yin, Y. Wu, X.G. Xu, H. Wang, J.P. Wang, Y. Jiang. AIP Advances 4, 12, 127156 (2014).

Редактор Т.Н. Василевская 